\title{
Aplikasi fungi mikoriza arbuskula Glomus sp. dan Trichoderma sp. sebagai pupuk hayati dan biostimulator pertumbuhan tanaman tomat (Solanum lycopersicum L.)
}

\author{
Application arbuscular mycorrhizal fungi Glomus sp. and Trichoderma sp. as \\ biofertilizer and biostimulator of tomatoes growth (Solanum lycopersicum L.)
}

\author{
Anak Agung Yulia Anggiani, Meitini Wahyuni Proborini*, I Ketut Muksin, Inna Narayani \\ Program Studi Biologi, Fakultas Matematika dan Ilmu Pengetahuan Alam, Universitas Udayana \\ Jl. Raya Kampus Unud Jimbaran, Kuta Selatan, Badung - Bali 80361 - Indonesia
}

*Email: pmeitini@unud.ac.id

Diterima 20 Juni 2021 Disetujui 30 September 2021

\section{INTISARI}

Tomat (Solanum lycopersicum L.) merupakan komoditas hortikultura yang memiliki banyak manfaat dan potensial untuk dikembangkan. Permintaan pasar terhadap buah tomat meningkat, namun produksi tomat di Bali mengalami penurunan karena faktor biotik dan abiotik. Upaya untuk meningkatkan pertumbuhan tanaman tomat yaitu menggunakan FMA Glomus sp. dan Trichoderma sp. yang berfungsi sebagai pupuk hayati dan biostimulator. Penelitian dilaksanakan pada November 2020 sampai Februari 2021 dan bertujuan untuk menganalisis pengaruh pemberian FMA, Trichoderma sp. dan kombinasinya terhadap pertumbuhan tanaman tomat. Lokasi penelitian di Greenhouse dan Laboratorium Taksonomi Tumbuhan Prodi Biologi Fakultas MIPA Universitas Udayana. Rancangan penelitian menggunakan Rancangan Acak Kelompok (RAK) Faktorial dengan dua faktor dan tiga kali ulangan. Faktor pertama dosis FMA Glomus (0, 100, 150 dan 200 spora per tanaman), faktor kedua dosis Trichoderma (0, 10 dan $20 \mathrm{~mL}$ per tanaman). Data dianalisis menggunakan Analysis of Variance (ANOVA) dan dilanjutkan dengan analisis Duncan Multiple Range Test (DMRT). Hasil penelitian menunjukkan bahwa aplikasi FMA Glomus sp. 150 spora per tanaman dapat meningkatkan tinggi tanaman, panjang akar, jumlah kuntum bunga per tanaman, berat kering total tanaman dan mendapatkan persentase kolonisasi FMA tertinggi sebesar 35\% (kategori sedang).

Kata kunci: dosis, hortikultura, komoditas, produktivitas, Solanaceae

\begin{abstract}
Tomato (Solanum lycopersicum L.) is a horticultural crop that has many benefits and potential to be developed. Market demand for tomatoes is increasing, but tomato production in Bali has decreased due to biotic and abiotic factors. One of efforts to increase tomato production is by using the Mycorrhizal Arbuscular Fungi (FMA) Glomus sp. and Trichoderma sp. which act as a biofertilizer and biostimulator. The study was conducted in November 2020 until February 2021 and aims to analyze the effect of AMF, Trichoderma, and combinations on the growth of tomato plants. Research site was at the Greenhouse and the Laboratory of Plant Taxonomy in the Department of Biology Faculty of Mathematics and Natural Sciences Udayana University. The experiment used factorial Randomized Block Design (RBD) with two factors, three replicates. First factor was the dose of AMF Glomus (0, 100, 150, and 200 spores per plant) and the second factor was the dose of Trichoderma $(0,10$, and $20 \mathrm{~mL}$ per plant). Data of this study was analyzed using Analysis of Variance (ANOVA) followed by Duncan Multiple Range Test (DMRT). The
\end{abstract}


result showed that AMF Glomus 150 spores increased plant height, root length, number of flower bunches, dry plant mass, and obtained the highest AMF colonization percentage at 35\% (medium category).

Keywords: commodity, dosage, horticulture, productivity, Solanaceae

\section{PENDAHULUAN}

Tomat (Solanum lycopersicum L.) merupakan salah satu komoditas hortikultura yang potensial untuk dikembangkan karena memiliki berbagai manfaat. Buah tomat dapat dikonsumsi secara langsung atau diolah menjadi sayuran, bumbu masak, saos dan manisan. Buah tomat mengandung likopen dan flavonoid, berfungsi sebagai antioksidan yang dapat mencegah radikal bebas. Kandungan vitamin $\mathrm{C}$ pada buah tomat berfungsi untuk memelihara kesehatan gigi dan gusi (Dalimartha, 2011). Kandungan lainnya yaitu vitamin A, E, protein, karbohidrat, zat besi, kalsium, magnesium, fosfat, kalium, dan serat yang dapat meningkatkan kesehatan tubuh, melancarkan sirkulasi darah dan metabolisme tubuh (Ariyanta et al., 2015; Surbakti \& Berawi, 2016).

Banyaknya kandungan nutrisi dan manfaat dari buah tomat, menyebabkan meningkatnya permintaan pasar terhadap buah tomat, namun hal tersebut berbanding terbalik dengan produksi buah tomat di Bali. Badan Pusat Statistik Provinsi Bali (2020), menyatakan bahwa produksi tomat di Bali selama tahun 2015-2019 mengalami fluktuasi. Tahun 2019 mengalami penurunan produksi mencapai 10.432 ton, sehingga perlu dilakukan upaya untuk meningkatkan produksi tomat di Bali.

Berbagai upaya telah dilakukan petani untuk meningkatkan pertumbuhan bibit tomat yaitu dengan menggunakan pupuk anorganik/kimia (Sianturi et al., 2017). Pupuk anorganik dapat meningkatkan hasil panen buah tomat lebih cepat dibandingkan dengan pupuk hayati, namun penggunaan pupuk anorganik dalam jangka panjang dapat menurunkan kesuburan tanah, merusak keragaman hayati di dalam tanah dan meningkatkan organisme pengganggu tumbuhan, sehingga penggunaan pupuk anorganik dapat diimbangi dengan penggunaan agen hayati seperti
FMA dan Trichoderma sp. sebagai suplemen pupuk (Barus, 2011).

Fungi Mikoriza Arbuskula (FMA) merupakan salah satu jenis mikoriza dan biostimulator yang dalam asosiasinya dengan akar tumbuhan akan menginfeksi masuk ke dalam jaringan sel korteks akar (Istigfaiyah, 2018). FMA dapat meningkatkan toleransi tanaman terhadap kekeringan dan lahan kritis. Selain itu FMA mampu meningkatkan pertumbuhan dan hasil tanaman dengan mekanisme penyerapan air serta unsur hara pada perakaran tanaman dan mendistribusikannya ke seluruh bagian tanaman (Damanik dan Suryanto, 2018).

Hasil penelitian Windasari et al. (2019), menyatakan bahwa FMA dapat digunakan sebagai biostimulator pertumbuhan tanaman jagung. FMA jenis Glomus spp. dapat meningkatkan pertumbuhan dan jumlah polong kedelai dalam skala greenhouse (Triarta et al., 2019). Penelitian Krisdayani et al. (2020), menunjukkan bahwa kombinasi FMA Glomus spp. dan Trichoderma spp. mampu mempercepat dan meningkatkan fase pembibitan pada tanaman sengon. Selain penggunaan FMA sebagai pupuk hayati, Syamsiah \& Rahmawati (2017), menyatakan bahwa-inokulasi jamur Trichoderma spp. dapat digunakan sebagai biostimulator yang berpengaruh terhadap pertumbuhan bibit padi Pandanwangi Cianjur.

Penelitian mengenai pengaruh kombinasi FMA dan Trichoderma pada beberapa jenis tanaman telah dilaporkan, namun informasi tentang aplikasi FMA dan jamur Trichoderma sebagai pupuk hayati untuk mempercepat pertumbuhan bibit atau tanaman tomat sejauh ini masih sedikit, sehingga perlu dilakukan penelitian mengenai aplikasi kombinasi FMA dan Trichoderma sebagai pupuk hayati dan biostimulator untuk meningkatkan pertumbuhan tanaman tomat. Penelitian ini bertujuan untuk menganalisis 
pengaruh pemberian FMA Glomus sp. dan Trichoderma sp. serta kombinasinya terhadap pertumbuhan tanaman tomat.

\section{MATERI DAN METODE}

\section{Tempat dan waktu penelitian}

Penelitian dilaksanakan di greenhouse dan Laboratorium Taksonomi Tumbuhan Program Studi Biologi Fakultas Matematika dan Ilmu Pengetahuan Alam, Universitas Udayana, pada bulan November 2020-Februari 2021.

\section{Bahan dan alat}

Bahan yang digunakan dalam penelitian yaitu benih tomat varietas Vitalia. Fungi Mikoriza Arbuskula (FMA) Glomus sp. hasil perbanyakan dari kebun jagung di green house Program Studi Biologi FMIPA Universitas Udayana, jamur Trichoderma sp. koleksi Laboratorium Taksonomi Tumbuhan Program Studi Biologi FMIPA Universitas Udayana, Potato Dextrose Agar (PDA), antibiotik, tanah, pasir, air, dan pupuk $\mathrm{KNO}_{3}$ merah, $\mathrm{KOH} 10 \%$, methylene blue $0,05 \%$, asam asetat glasial, akuades, gliserin, $\mathrm{HCl}$ $1 \%$

Alat yang digunakan dalam penelitian yaitu saringan bertingkat merek "Analysensieb Eckhard 5657 Haan W. Germany" dengan ukuran sebesar 200, 100, 65, dan $45 \mu \mathrm{m}$, seedling tray, polybag ukuran $35 \times 35 \mathrm{~cm}$, penyangga/ajir, tali rafia, meteran, kompor, panci, hot plate, cawan Petri, Erlenmeyer, scalpel, pipet tetes, jarum ent, mikroskop binokuler, timbangan digital, kamera.

\section{Metode}

\section{Penyaringan FMA Glomus sp.}

Penyaringan spora FMA Glomus sp. dilakukan dengan metode penyaringan basah (Brundett et al., 1996). Tanah dan air dimasukkan dalam wadah dengan perbandingan 1:4, Suspensi diaduk dan diendapkan selama 5 menit. Suspensi disaring di bawah air mengalir dengan saringan bertingkat ukuran 200, 100, 65, dan $45 \mu \mathrm{m}$. Suspensi hasil penyaringan dengan saringan ukuran 65 dan $45 \mu \mathrm{m}$ disimpan dalam botol plastik. Jumlah spora dihitung dengan cara suspensi spora hasil penyaringan dipipet dengan pipet tetes dan diletakkan di dalam cawan petri, diamati di bawah mikroskop (Proborini, 2011).

\section{Reisolasi Jamur Trichoderma}

Jamur direisolasi pada media PDA dan dilakukan di dekat api bunsen. Isolat jamur Trichoderma sp. diinkubasi pada suhu ruang hingga jamur tumbuh.

\section{Persiapan media tanam}

Media tanam tanah dan pasir (1:1) disterilisasi dengan panci dan kompor pada suhu $100^{\circ} \mathrm{C}$ selama 3 jam. Media tanam yang telah disterilisasi, kemudian ditunggu hingga dingin. Media tanam ditimbang sebanyak $6 \mathrm{~kg}$, lalu dimasukkan ke dalam polybag.

\section{Inokulasi spora FMA dan Trichoderma}

Lubang tanam dibuat sedalam $\pm 5 \mathrm{~cm}$. Suspensi FMA Glomus sp. diambil sebanyak (100, 150, 200 spora per tanaman). Masing-masing dosis spora FMA dituangkan ke dalam lubang tanam sesuai label perlakuan. Trichoderma sp. diaplikasikan dalam bentuk suspensi dosis (10, 20 $\mathrm{mL}$ per tanaman) dan dituangkan ke dalam lubang tanam sesuai label perlakuan. Inokulasi FMA dan atau Trichoderma dilakukan sebanyak satu kali sebelum bibit tomat ditanam dalam polybag.

\section{Rancangan percobaan}

Rancangan penelitian menggunakan Rancangan Acak Kelompok (RAK) faktorial dengan 2 faktor. Faktor pertama yaitu FMA Glomus sp. (Dosis FMA Glomus sp. 0, 100, 150, dan 200 spora). Faktor kedua yaitu Trichoderma sp. (Dosis Trichoderma sp. 0, 10 dan $20 \mathrm{~mL}$ ), sehingga diperoleh 12 satuan perlakuan. Masingmasing satuan perlakuan diulang sebanyak 3 kali dan diperoleh kombinasi perlakuan sebanyak 36 tanaman. Masing-masing kombinasi perlakuan terdapat 3 tanaman sampel, sehingga total unit tanaman sebanyak 108 . 


\section{Penanaman bibit tomat}

Bibit tomat yang telah berusia 25-30 hari dan telah memiliki 3-4 daun sempurna, kemudian dipindahkan ke dalam polybag yang media tanamnya telah diberikan perlakuan (FMA Glomus sp. dan atau Trichoderma sp.).

\section{Pemupukan}

Pupuk $\mathrm{KNO}_{3}$ merah ditebarkan ke media tanam dengan dosis $5 \mathrm{~g} /$ tanaman sebanyak satu kali menjelang bunga muncul pertama kali.

\section{Persentase kolonisasi FMA Glomus sp.}

Proses preparasi akar dengan metode Kormanik \& Mc. Graw (1982). Proses pertama yaitu clearing, akar dicuci dengan air dan dipotong dengan ukuran $\pm 2 \mathrm{~cm}$. Potongan akar direndam dalam larutan $\mathrm{KOH} 10 \%$ selama 24 jam dalam suhu ruang hingga akar tampak transparan. Akar dibilas dengan air mengalir hingga bersih dan tidak licin. Akar direndam dalam larutan $\mathrm{HCl}$ $1 \%$ selama 5-10 menit.

Tahap staining, akar direndam selama 24 jam dalam larutan gliserin, asam asetat glasial dan akuades (2:2:1), kemudian direndam dalam methylene blue $0,05 \%$ selama 7 menit. Selanjutnya tahap destaining yaitu akar direndam dalam larutan larutan gliserin, asam asetat glasial dan akuades (2:2:1).

Perhitungan kolonisasi FMA pada akar dilakukan dengan metode slide (Giovannetti \& Mosse, 1980). Potongan akar diambil sebanyak 15-20 potong, disusun di atas kaca preparat dan diamati di bawah mikroskop. Akar yang terinfeksi hifa, vesikel, dan arbuskula diberi tanda $(+)$.

Rumus persentase kolonisasi FMA:

$$
\frac{\text { Jumlah akar yang terinfeksi }}{\text { Jumlah akar yang diamati }} \times 100 \%
$$

Persentase kolonisasi FMA pada akar tanaman memiliki beberapa kriteria menurut Setiadi (1992), yang disajikan pada Tabel 1.
Tabel 1. Kriteria kolonisasi FMA

\begin{tabular}{ccc}
\hline Kelas & Persentase $(\boldsymbol{\%})$ & Kriteria \\
\hline 1 & $0-5$ & Sangat rendah \\
2 & $6-25$ & Rendah \\
3 & $26-50$ & Sedang \\
4 & $51-75$ & Tinggi \\
5 & $76-100$ & Sangat tinggi \\
\hline
\end{tabular}

\section{Analisis data}

Data kuantitatif yang diperoleh dianalisis menggunakan Analysis of Variance (ANOVA), jika diperoleh hasil yang berbeda nyata $\alpha<0,05$, maka dilanjutkan dengan analisis Duncan Multiple Range Test (DMRT).

\section{HASIL}

\section{Kolonisasi FMA}

Hasil pengamatan kolonisasi FMA pada akar tanaman tomat secara mikroskopis menunjukkan bahwa tidak terdapat kolonisasi pada dosis FMA 0 spora dan terdapat kolonisasi pada dosis FMA 100, 150 dan 200 spora. Preparat akar tanaman tomat yang tidak terdapat kolonisasi dan yang terdapat kolonisasi FMA secara mikroskopis disajikan pada Gambar 1.

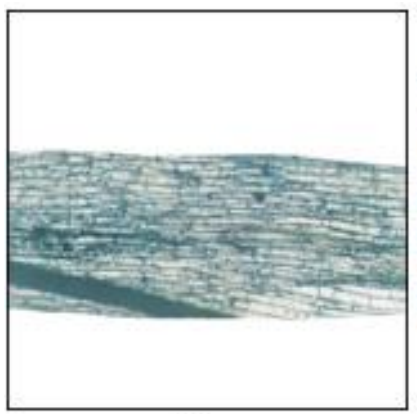

(a)

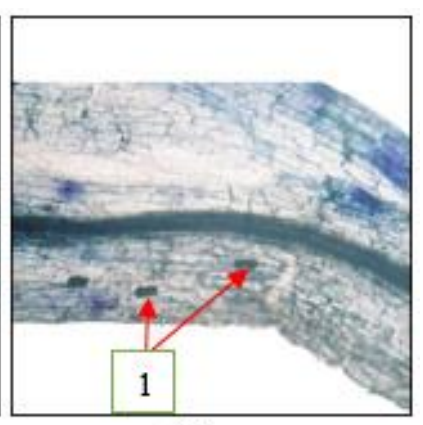

(b)
Gambar 1. Preparat akar tanaman tomat, perbesaran 100X (a) akar yang tidak terkolonisasi FMA (b) akar yang terdapat kolonisasi FMA (1.Vesikula)

Gambar 1a menunjukkan bahwa tidak terdapat kolonisasi FMA pada perlakuan dosis FMA 0 spora yang ditandai dengan tidak adanya struktur vesikula, arbuskula dan hifa. Namun demikian, terdapat kolonisasi pada perlakuan dosis FMA 100, 150, dan 200 spora yang ditandai dengan adanya struktur berupa vesikula yang ditunjukkan 
oleh nomor 1. Berdasarkan hasil pengamatan kolonisasi FMA (Gambar 1) dan perhitungan kolonisasi FMA pada akar tanaman tomat secara mikroskopis, diperoleh hasil persentase kolonisasi FMA pada akar tanaman (Gambar 2).

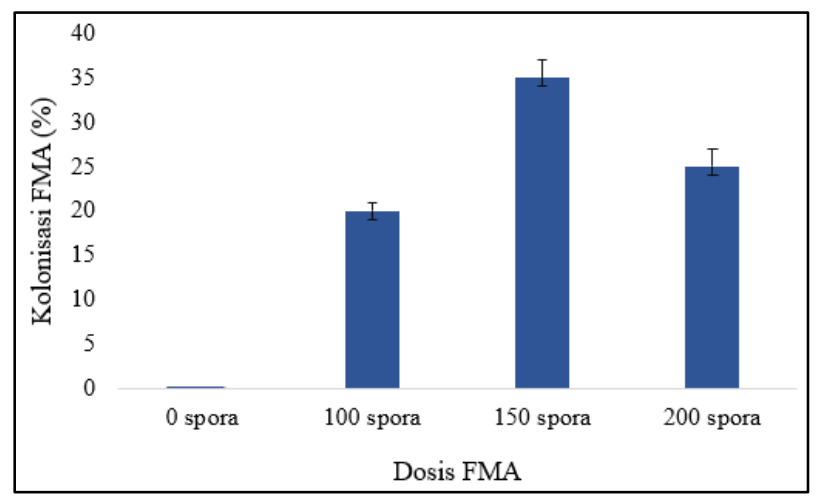

Gambar 2. Persentase Kolonisasi FMA pada akar tanaman

Gambar 2 menunjukkan bahwa perlakuan dosis FMA 0, 100, 150 dan 200 spora menghasilkan persentase kolonisasi berturut-turut sebesar $0 \%$, 20\%, 35\%, 25\%. Berdasarkan kriteria kolonisasi FMA (Setiadi, 1992), persentase kolonisasi FMA 0 spora tergolong sangat rendah. Persentase kolonisasi FMA dosis 100 dan 200 spora tergolong rendah, sedangkan persentase FMA dosis 150 spora tergolong kriteria sedang dengan persentase sebesar $35 \%$.

\section{Tinggi tanaman}

Hasil Analysis of Variance (ANOVA) menunjukkan bahwa faktor pemberian FMA dan interaksi kedua faktor (FMA*Trichoderma) berpengaruh nyata, sedangkan faktor pemberian Trichoderma tidak berpengaruh nyata terhadap tinggi tanaman. Rerata tinggi tanaman (Tabel 2).

Rerata tinggi tanaman tomat Varietas Vitalia berkisar 170,16-186,33 cm. Interaksi kedua faktor (FMA*Trichoderma) berpengaruh nyata terhadap tinggi tanaman tomat. Interaksi kedua faktor yang menghasilkan rerata tanaman tertinggi yaitu perlakuan M2T0 (FMA 150 spora + Trichoderma $0 \mathrm{~mL}$ ) sebesar $186,33 \mathrm{~cm}$, sedangkan perlakuan kontrol M0T0 (FMA 0 spora + Trichoderma 0 $\mathrm{mL})$ menghasilkan tinggi tanaman terendah sebesar 170,16 cm (Tabel 2).
Tabel 2. Rerata tinggi tanaman pada perlakuan interaksi kedua faktor (FMA*Trichoderma)

\begin{tabular}{cc}
\hline $\begin{array}{c}\text { Interaksi FMA }(\mathbf{M}) \\
\text { dan Trichoderma }(\mathbf{T})\end{array}$ & Tinggi tanaman $(\mathbf{c m})$ \\
\hline M0T0 & $170,16 \pm 1.66 \mathrm{a}$ \\
M0T1 & $177,33 \pm 7.60 \mathrm{abc}$ \\
M0T2 & $179,26 \pm 4.08 \mathrm{abc}$ \\
M1T0 & $177,90 \pm 1.50 \mathrm{abc}$ \\
M1T1 & $178,93 \pm 5.33 \mathrm{abc}$ \\
M1T2 & $180,00 \pm 4,26 \mathrm{bc}$ \\
M2T0 & $186,33 \pm 5,90 \mathrm{c}$ \\
M2T1 & $180,70 \pm 6,44 \mathrm{bc}$ \\
M2T2 & $183,46 \pm 2,64 \mathrm{c}$ \\
M3T0 & $179,33 \pm 3,11 \mathrm{abc}$ \\
M3T1 & $182,70 \pm 6,55 \mathrm{bc}$ \\
M3T2 & $173,33 \pm 5,22 \mathrm{ab}$ \\
DMRT 5\% & $\mathbf{1 , 8 0}$ \\
\hline
\end{tabular}

Keterangan: Angka yang diikuti notasi yang berbeda pada kolom yang sama, menunjukkan berbeda nyata berdasarkan uji DMRT 5\%.

\section{Jumlah cabang primer}

Hasil Analysis of Variance (ANOVA) menunjukkan bahwa faktor pemberian FMA, Trichoderma, dan interaksi kedua faktor (FMA*Trichoderma) tidak berpengaruh nyata terhadap jumlah cabang primer. Rerata jumlah cabang primer tanaman tomat Varietas Vitalia (Tabel 3).

Tabel 3. Rerata jumlah cabang primer pada perlakuan interaksi kedua faktor (FMA*Trichoderma)

\begin{tabular}{cc}
\hline $\begin{array}{c}\text { Interaksi FMA }(\mathbf{M}) \\
\text { dan Trichoderma }(\mathbf{T})\end{array}$ & $\begin{array}{c}\text { Jumlah cabang } \\
\text { primer }\end{array}$ \\
\hline M0T0 & $27,56 \pm 1,25 \mathrm{tn}$ \\
M0T1 & $30,43 \pm 1,69 \mathrm{tn}$ \\
M0T2 & $30,56 \pm 1,20 \mathrm{tn}$ \\
M1T0 & $31,56 \pm 0,51 \mathrm{tn}$ \\
M1T1 & $30,56 \pm 1,40 \mathrm{tn}$ \\
M1T2 & $30,66 \pm 2,08 \mathrm{tn}$ \\
M2T0 & $30,46 \pm 1,66 \mathrm{tn}$ \\
M2T1 & $30,56 \pm 2,01 \mathrm{tn}$ \\
M2T2 & $29,56 \pm 1,91 \mathrm{tn}$ \\
M3T0 & $28,66 \pm 1,35 \mathrm{tn}$ \\
M3T1 & $31,20 \pm 1,82 \mathrm{tn}$ \\
M3T2 & $29,23 \pm 1,36 \mathrm{tn}$ \\
DMT 5\% & tn \\
\hline
\end{tabular}

Keterangan: Angka yang diikuti notasi yang berbeda pada kolom yang sama, menunjukkan berbeda nyata berdasarkan uji DMRT 5\%. tn: tidak nyata

Rerata jumlah cabang primer tanaman tomat Varietas Vitalia berkisar 27,56-31,56 cabang. Pengaruh pemberian FMA, Trichoderma, dan interaksi kedua faktor (FMA*Trichoderma) 
menghasilkan jumlah cabang primer yang tidak berbeda nyata, namun terdapat kecenderungan bahwa perlakuan M1T0 (FMA 100 spora + Trichoderma $0 \mathrm{~mL}$ ) menghasilkan rerata jumlah cabang terbanyak yaitu 31,56 cabang. Perlakuan M0T0 (FMA 0 spora + Trichoderma $0 \mathrm{~mL}$ ) menghasilkan rerata jumlah cabang primer yang paling sedikit yaitu 27,56 cabang (Tabel 3).

\section{Panjang akar}

Hasil Analysis of Variance (ANOVA) menunjukkan bahwa faktor pemberian FMA dan interaksi kedua faktor (FMA*Trichoderma) berpengaruh nyata terhadap panjang akar. Faktor pemberian Trichoderma tidak berpengaruh nyata terhadap panjang akar. Rerata panjang akar tanaman tomat Varietas Vitalia disajikan pada Tabel 4.

Tabel 4. Rerata panjang akar pada perlakuan interaksi kedua faktor (FMA*Trichoderma)

\begin{tabular}{cc}
\hline $\begin{array}{c}\text { Interaksi FMA }(\mathbf{M}) \\
\text { dan Trichoderma }(\mathbf{T})\end{array}$ & Panjang akar $(\mathbf{c m})$ \\
\hline M0T0 & $52,10 \pm 1,96 \mathrm{a}$ \\
M0T1 & $61,63 \pm 1,55 \mathrm{bcde}$ \\
M0T2 & $68,03 \pm 2,53 \mathrm{efg}$ \\
M1T0 & $66,66 \pm 3,27 \mathrm{def}$ \\
M1T1 & $69,13 \pm 7,57 \mathrm{efg}$ \\
M1T2 & $56,30 \pm 2,30 \mathrm{ab}$ \\
M2T0 & $75,13 \pm 1,00 \mathrm{~g}$ \\
M2T1 & $59,93 \pm 8,41 \mathrm{bcd}$ \\
M2T2 & $70,36 \pm 3,91 \mathrm{fg}$ \\
M3T0 & $64,73 \pm 4,36 \mathrm{cdef}$ \\
M3T1 & $57,43 \pm 1,85 \mathrm{abc}$ \\
M3T2 & $61,53 \pm 2,34 \mathrm{bcde}$ \\
DMRT 5\% & $\mathbf{3 , 0 3}$ \\
\hline
\end{tabular}

Keterangan: Angka yang diikuti notasi yang berbeda pada kolom yang sama, menunjukkan berbeda nyata berdasarkan uji DMRT 5\%.

Rerata panjang akar tanaman tomat Varietas Vitalia berkisar 52,10-75,13 cm. Interaksi kedua perlakuan (FMA* Trichoderma) menghasilkan panjang akar yang berbeda nyata. Interaksi kedua faktor menunjukkan bahwa perlakuan M2T0 (FMA 150 spora + Trichoderma $0 \mathrm{~mL}$ ) menghasilkan akar terpanjang yaitu $75,13 \mathrm{~cm}$. Perlakuan M0T0 (FMA 0 spora + Trichoderma 0 $\mathrm{mL}$ ) menghasilkan akar terpendek yaitu $52,10 \mathrm{~cm}$ (Tabel 4).

\section{Jumlah kuntum bunga per tanaman}

Berdasarkan hasil Analysis of Variance (ANOVA) terhadap jumlah kuntum bunga per tanaman menunjukkan bahwa faktor pemberian FMA dan interaksi kedua faktor (FMA*Trichoderma) berpengaruh nyata. Faktor pemberian Trichoderma tidak berpengaruh nyata. Rerata jumlah kuntum bunga per tanaman disajikan pada Tabel 5.

Tabel 5. Rerata jumlah kuntum bunga per tanaman pada perlakuan interaksi kedua faktor (FMA*Trichoderma)

\begin{tabular}{cc}
\hline $\begin{array}{c}\text { Interaksi FMA (M) } \\
\text { dan Trichoderma }(\mathbf{T})\end{array}$ & $\begin{array}{c}\text { Jumlah kuntum } \\
\text { bunga per tanaman }\end{array}$ \\
\hline M0T0 & $20,00 \pm 1,32 \mathrm{a}$ \\
M0T1 & $25,09 \pm 2,00 \mathrm{~b}$ \\
M0T2 & $28,57 \pm 1,24 \mathrm{bcd}$ \\
M1T0 & $27,95 \pm 0,32 \mathrm{bcd}$ \\
M1T1 & $30,53 \pm 4,06 \mathrm{bcd}$ \\
M1T2 & $31,01 \pm 1,00 \mathrm{~cd}$ \\
M2T0 & $32,84 \pm 2,23 \mathrm{~d}$ \\
M2T1 & $29.28 \pm 3,08 \mathrm{bcd}$ \\
M2T2 & $28,57 \pm 4,25 \mathrm{bcd}$ \\
M3T0 & $26,96 \pm 3,78 \mathrm{bc}$ \\
M3T1 & $26,99 \pm 4,34 \mathrm{bc}$ \\
M3T2 & $30,86 \pm 2,88 \mathrm{~cd}$ \\
DMRT 5\% & $\mathbf{1 , 7 8}$ \\
\hline
\end{tabular}

Keterangan: Angka yang diikuti notasi yang berbeda pada kolom yang sama, menunjukkan berbeda nyata berdasarkan uji DMRT 5\%.

Rerata jumlah kuntum bunga tanaman tomat Varietas Vitalia berkisar 20,00-32,84 kuntum per tanaman. Interaksi kedua faktor (FMA*Trichoderma) menunjukkan bahwa terdapat perbedaan nyata. Perlakuan yang menghasilkan jumlah kuntum bunga terbanyak yaitu M2T0 (FMA 150 spora + Trichoderma 0 mL) sebanyak 32,84 kuntum per tanaman. Perlakuan M0T0 (FMA 0 spora + Trichoderma 0 $\mathrm{mL}$ ) menghasilkan jumlah kuntum bunga paling sedikit yaitu sebanyak 20,00 kuntum per tanaman (Tabel 5).

\section{Berat kering total tanaman}

Berdasarkan hasil Analysis of Variance (ANOVA) menunjukkan bahwa faktor pemberian FMA dan interaksi kedua faktor (FMA*Trichoderma) berpengaruh nyata terhadap berat kering total tanaman. Faktor pemberian 
Trichoderma tidak berpengaruh nyata terhadap berat kering total tanaman. Rerata berat kering total tanaman disajikan pada Tabel 6.

Tabel 6. Rerata berat kering total tanaman pada perlakuan interaksi kedua faktor (FMA*Trichoderma)

\begin{tabular}{cc}
\hline $\begin{array}{c}\text { Interaksi FMA }(\mathbf{M}) \\
\text { dan Trichoderma }(\mathbf{T})\end{array}$ & $\begin{array}{c}\text { Berat kering total } \\
\text { tanaman }(\mathbf{g})\end{array}$ \\
\hline M0T0 & $23,30 \pm 1,08 \mathrm{a}$ \\
M0T1 & $28,10 \pm 1,94 \mathrm{bc}$ \\
M0T2 & $29,09 \pm 1,74 \mathrm{bc}$ \\
M1T0 & $30,28 \pm 0,81 \mathrm{bc}$ \\
M1T1 & $28,71 \pm 1,48 \mathrm{bc}$ \\
M1T2 & $30,23 \pm 1,12 \mathrm{bc}$ \\
M2T0 & $31,26 \pm 1,84 \mathrm{c}$ \\
M2T1 & $26,84 \pm 1,45 \mathrm{~b}$ \\
M2T2 & $28,86 \pm 1,44 \mathrm{bc}$ \\
M3T0 & $29,51 \pm 2,84 \mathrm{bc}$ \\
M3T1 & $28,47 \pm 2,31 \mathrm{bc}$ \\
M3T2 & $29,71 \pm 3,92 \mathrm{bc}$ \\
DMR 5\% & $\mathbf{1 , 1 9}$ \\
\hline
\end{tabular}

Keterangan: Angka yang diikuti notasi yang berbeda pada kolom yang sama, menunjukkan berbeda nyata berdasarkan uji DMRT 5\%.

Rerata berat kering total tanaman tomat Varietas Vitalia berkisar 23,30-31,26 g. Interaksi kedua faktor (FMA*Trichoderma) berpengaruh nyata terhadap berat kering total. Interaksi kedua faktor menunjukkan bahwa perlakuan M2T0 (FMA 150 spora + Trichoderma $0 \mathrm{~mL}$ ) menghasilkan berat kering total tertinggi sebesar 31,26 g, sedangkan perlakuan M0T0 (FMA 0 spora + Trichoderma $0 \mathrm{~mL}$ ) menghasilkan berat kering total tanaman terendah sebesar 23,30 g.

\section{PEMBAHASAN}

\section{Kolonisasi FMA}

Hasil penelitian menunjukkan bahwa pada perlakuan 100, 150 dan 200 spora per tanaman pengamatan pada korteks akar tanaman tomat terdapat struktur hifa internal dan vesikula. Vesikula merupakan pembengkakan pada hifa yang berbentuk lonjong atau bulat, mengandung cairan lemak yang berfungsi sebagai tempat menyimpan nutrisi. Adanya vesikel pada bagian korteks akar menunjukkan bahwa aktivitas hifa internal cukup intensif sehingga FMA mampu menghasilkan vesikel sebagai cadangan makanan bagi FMA tersebut untuk bisa bertahan hidup dan bereproduksi menghasilkan spora (Pebriansyah, 2012).

Gambar 2 menunjukkan bahwa tidak terdapat kolonisasi pada dosis FMA 0 spora, sedangkan pada dosis FMA 150 spora menghasilkan persentase kolonisasi tertinggi. Hal ini menandakan bahwa pada kontrol atau tanaman tanpa pemberian FMA (0 spora) tidak akan terjadi kolonisasi dari FMA dari tanah sebagai media karena tanah yang digunakan adalah tanah steril. Selanjutnya pada tanaman yang diberikan FMA sebanyak 150 spora dapat dikatakan sebagai kondisi yang optimal untuk FMA dalam meningkatkan pertumbuhan akar tanaman tomat, meskipun persentase kolonisasinya termasuk kriteria sedang.

Pemberian dosis FMA 200 spora menghasilkan persentase kolonisasi yang lebih rendah daripada dosis FMA 150 spora. Hal ini menunukkan bahwa semakin banyak dosis FMA yang diinokulasikan, maka semakin banyak nutrisi dari tanaman inang yang diperlukan FMA untuk kelangsungan hidupnya. Jika tanaman inang tidak mampu memberikan nutrisi berupa karbohidrat dan karbon dalam dosis FMA yang melampaui optimal, maka FMA akan bekerja lebih lambat dalam menginfeksi akar tanaman sehingga menyebabkan rendahnya derajat kolonisasi (Karnedi, 2017).

Infektivitas antara FMA dengan tanaman inang sangat beragam dan dipengaruhi oleh jenis FMA, jenis tanaman inang, dan kondisi lingkungan, serta interaksi antara FMA dengan senyawasenyawa yang dihasilkan oleh tanaman inang (Hadianur et al., 2016; Yoseva et al., 2014). Kolonisasi FMA dipengaruhi oleh kompatibilitas FMA terhadap jenis atau varietas tanaman inang. Kuswandi \& Sugiarto (2015), menyatakan bahwa tanaman tomat varietas Revalina dan Martha yang diinokulasikan FMA Glomus sp. menghasilkan persentase kolonisasi FMA yang berbeda antar varietas. Hal tersebut karena perbedaan genotipe yang diiringi oleh perbedaan reaksi pada masingmasing varietas tanaman terhadap jenis FMA.

\section{Tinggi tanaman}


Hasil penelitian menunjukkan bahwa perlakuan M2T0 (FMA 150 spora + Trichoderma $0 \mathrm{~mL}$ ) menghasilkan tanaman tertinggi. Hal ini menunjukkan bahwa dosis FMA 150 spora merupakan dosis optimal yang efektif untuk meningkatkan tinggi tanaman.

Hasil penelitian menunjukkan bahwa pemberian Trichoderma tidak berpengaruh terhadap tinggi tanaman. Hal ini dapat disebabkan karena aplikasi Trichoderma saat pindah tanam kurang efektif. Menurut Simarmata et al. (2004), aplikasi Trichoderma lebih efektif pada masa penyemaian, sehingga saat tanaman dipindahkan ke polybag, Trichoderma telah menginfeksi akar tanaman. Subhan et al. (2012), menyatakan bahwa Trichoderma tidak dapat meningkatkan tinggi tanaman tomat karena aplikasi Trichoderma dengan cara ditambahkan di lubang tanam sebelum pindah tanam kurang efektif.

Fungi mikoriza arbuskula (FMA) 150 spora merupakan dosis yang optimal untuk meningkatkan tinggi tanaman karena pada dosis ini simbiosis mutualisme antara FMA dan akar tanaman telah berlangsung dengan baik. Mekanisme simbiosis mutualisme antara tanaman inang dengan FMA yaitu FMA akan menghasilkan hifa eksternal untuk memperluas bidang serapan akar tanaman terhadap air dan unsur hara, sebagai timbal baliknya tanaman akan memberikan nutrisi berupa karbohidrat (dalam bentuk gula sederhana) dan karbon untuk pertumbuhan FMA (Karnedi, 2017).

Simbiosis mutualisme antara FMA dan tanaman inang akan berlangsung dengan baik jika tanaman inang mendapatkan dosis FMA yang optimal. Pemberian FMA yang melampaui batas toleran menyebabkan semakin banyak nutrisi dari tanaman inang yang diperlukan FMA untuk kelangsungan hidupnya. Jika tanaman inang tidak mampu memberikan nutrisi pada dosis FMA yang melampaui batas toleran, maka FMA akan bekerja lebih lambat dalam menginfeksi akar tanaman sehingga menyebabkan pertumbuhan tanaman tidak maksimal (Oktaviana et al., 2019).
Pemberian FMA 150 spora efektif untuk meningkatkan tinggi tanaman sebab FMA pada dosis yang optimal dapat meningkatkan serapan air dan unsur hara yang digunakan dalam proses metabolisme tanaman, sehingga dapat menstimulasi pertumbuhan tinggi tanaman (Valentine et al., 2017). FMA dapat memacu pembentukan hormon-hormon pertumbuhan tanaman, seperti auksin dan sitokinin yang berfungsi untuk pembelahan dan pemanjangan sel-sel tanaman (Mutiarahma et al., 2020).

\section{Jumlah cabang primer}

Hasil penelitian menunjukkan bahwa interaksi kedua faktor (FMA*Trichoderma) tidak dapat meningkatkan jumlah cabang primer. Rerata jumlah cabang primer berkisar 27,56-31,56 cabang. Secara statistik pada seluruh perlakuan tidak terdapat perbedaan nyata, akan tetapi seluruh perlakuan menghasilkan jumlah cabang primer yang lebih banyak dibandingkan dengan perlakuan kontrol (M0T0). Perlakuan M0T0 hanya menghasilkan jumlah cabang primer sebanyak 27,56, sedangkan perlakuan lainnya menghasilkan jumlah cabang primer sebanyak 29,23-31,56 cabang.

Sesuai dengan penelitian Kuswandi \& Sugiarto (2015), yang menyatakan bahwa pemberian FMA tidak dapat meningkatkan jumlah cabang tanaman tomat Varietas Revalina dan Martha. Soverda (2010), menyatakan bahwa pemberian FMA tidak dapat meningkatkan jumlah cabang primer tanaman kedelai. Hal ini disebabkan karena jumlah cabang primer dipengaruhi oleh faktor genetik tanaman.

\section{Panjang akar}

Hasil penelitian menunjukkan bahwa perlakuan M2T0 (FMA 150 spora + Trichoderma $0 \mathrm{~mL}$ ) menghasilkan akar terpanjang. Hal ini menunjukkan bahwa dosis FMA 150 spora efektif untuk meningkatkan panjang akar tanaman tomat.

Fungi mikoriza arbuskula dapat menginfeksi akar tanaman inang, kemudian menghasilkan hifa secara intensif. Hifa tersebut akan memperluas permukaan akar, sehingga dapat meningkatkan 
kapasitas penyerapan unsur hara, khususnya unsur $\mathrm{P}$ yang dibutuhkan oleh tanaman dalam jumlah yang cukup (Ulfa et al., 2009; Wicaksono et al., 2014). Ukuran hifa yang lebih kecil dan halus dari rambut-rambut akar memungkinkan hifa dapat menembus pori-pori tanah yang kecil (mikro), sehingga hifa mampu menyerap air pada daerah rhizosfer yang kadar airnya rendah (Kuswandi \& Sugiarto, 2015).

Hifa FMA dapat menghasilkan senyawa glikoprotein glomalin yang berperan dalam meningkatkan agregrat tanah. Glikoprotein glomalin dihasilkan dari sekresi hifa eksternal bersama enzim-enzim dan senyawa polisakarida lainnya (Yusrinawati \& Sudantha, 2016). Glikoprotein glomalin akan mengikat butiran tanah menjadi agregat mikro, selanjutnya diubah menjadi agregat makro secara mekanis oleh hifa FMA. Perubahan agregat mikro menjadi agregat makro menyebabkan struktur tanah lebih gembur dan subur (Br Ginting et al., 2018).

\section{Jumlah kuntum bunga per tanaman}

Hasil penelitian menunjukkan bahwa perlakuan M2T0 (FMA 150 spora + Trichoderma $0 \mathrm{~mL}$ ) menghasilkan jumlah kuntum bunga per tanaman paling banyak. Hal ini menunjukkan bahwa dosis FMA 150 spora efektif untuk meningkatkan jumlah kuntum bunga per tanaman.

FMA mampu menyerap unsur hara yang diperlukan tanaman dan mempengaruhi keseimbangan hormon pada akar, sehingga mampu mempengaruhi proses pembungaan. FMA dapat meningkatkan serapan unsur $\mathrm{P}$ oleh akar tanaman. FMA menghasilkan enzim fosfatase yang dapat meningkatkan jumlah $P$ tidak terlarut menjadi $\mathrm{P}$ terlarut, sehingga mempercepat dan memudahkan penyerapan unsur $\mathrm{P}$ oleh hifa FMA dan akan diteruskan ke akar tanaman inang (Aprilia, 2013).

\section{Berat kering total tanaman}

Hasil penelitian menunjukkan bahwa perlakuan M2T0 (FMA 150 spora + Trichoderma $0 \mathrm{~mL}$ ) meghasilkan berat kering total tanaman tertinggi.
Hal ini menunjukkan bahwa dosis FMA 150 spora efektif untuk meningkatkan berat kering tanaman.

Tanaman memerlukan unsur hara, air dan cahaya matahari selama proses fotosintesis, pada akhir proses fotosintesis akan menghasilkan fotosintat. Selanjutnya fotosintat tersebut akan ditimbun dalam organ-organ tanaman seperti batang, daun, buah, dan biji. Fotosintat yang tertimbun pada organ tanaman menyebabkan bertambahnya berat kering tanaman. Hal ini menunjukkan bahwa tanaman yang memiliki pertumbuhan dan perkembangan yang baik, akan memiliki berat kering yang lebih tinggi (Wahyu et al., 2013).

Berat kering tanaman dipengaruhi oleh kelangsungan simbiosis FMA dan tanaman inang. Inokulasi FMA pada dosis optimal, akan meningkatkan serapan unsur hara dan air, sehingga proses pertumbuhan tanaman berlangsung dengan baik. Tanaman yang memiliki pertumbuhan yang optimal akan memiliki fotosintat yang lebih banyak, sehingga dapat meningkatkan berat kering tanaman (Wahyu et al., 2013).

\section{SIMPULAN}

Fungi Mikoriza Arbuskula (FMA) Glomus sp. dosis 150 spora mampu meningkatkan tinggi tanaman, panjang akar, jumlah kuntum bunga per tanaman, berat kering total tanaman, serta menghasilkan persentase kolonisasi FMA sebesar 35\% (kriteria sedang). Kombinasi dosis FMA Glomus sp. dan Trichoderma sp. belum mampu menghasilkan pertumbuhan terbaik.

\section{UCAPAN TERIMA KASIH}

Ucapan terima kasih ditujukan kepada Kepala Laboratorium Taksonomi Tumbuhan Prodi Biologi FMIPA Universitas Udayana yang telah menyediakan sarana dan fasilitas dalam penelitian ini dan kepada $\mathrm{Ni}$ Komang Nita Lestari, S.Si. yang telah memberikan bantuan dan dukungan selama penelitian. 


\section{KEPUSTAKAAN}

Ariyanta IPB, Sudiarta IP, Widaningsih D, Sumiartha IK, Wirya GAS, Utama MS. 2015. Penggunaan Trichoderma sp. dan penyambungan untuk mengendalikan penyakit utama tanaman tomat (Lycopersicum esculentum Mill.) di Desa Bangli, Kecamatan Baturiti, Kabupaten Tabanan. Jurnal Agroteknologi Tropika 4(1): $1-15$.

Aprilia DD. 2013. Pengaruh pemberian mikoriza Glomus fasciculatum terhadap pertumbuhan tanaman Euphorbia millii yang ditumbuhkan dalam media mengandung logam timbal $(\mathrm{Pb})$. Artikel Ilmiah. Jurusan Biologi Fakultas MIPA Institut Teknologi Sepuluh Nopember Surabaya. Surabaya.

Badan Pusat Statistik Provinsi Bali. 2020. Statistik hortikultura provinsi Bali 2019. BPS Provinsi Bali. Denpasar.

Barus AA. 2011. Pemanfaatan pupuk cair mikro untuk meningkatkan pertumbuhan dan produksi tanaman sawi (Brassica juncea L.) varietas Tosakan. Skripsi. Universitas Sumatera Utara. Medan.

Br Ginting AE, Yuliani, Dewi SK. 2018. Pengaruh mikoriza vesikular arbuskular dan Trichoderma harzianum pada pertumbuhan tanaman sawi hijau (Brassica juncea L.) di tanah liat dan tanah pasir. Jurnal LenteraBio 7(3): 231-235.

Brundett M, Brougher N, Dell B, Grove T, Malajczuk N. 1996. Working with mycorrhizas in forestry and agriculture. ACIAR Monograph. Canberra.

Dalimartha S. 2011. Khasiat buah dan sayur. Penebar Swadaya. Depok.

Damanik SA, Suryanto A. 2018. Efektivitas penggunaan mikoriza dan PGPR (plant growth promoting rhizobacteria) terhadap tanaman bawang merah (Allium ascalonicum L.) pada piva PVC sistem vertikultur. Jurnal Produksi Tanaman 6(4): 634-641.

Giovanneti M, Mosse B. 1980. An evaluation technique for measuring vesicular-arbuscular mycorrhiza infection in roots. Journal New Phytol 84: 489-500.

Hadianur, Syafruddin, Kesumawati E. 2016. Pengaruh jenis mikoriza arbuskular terhadap pertumbuhan dan hasil tanaman tomat
(Lycopersicum esculentum Mill.). Jurnal Agrista 20(3): 126-134.

Istigfaiyah L. 2018. Identifikasi dan karakterisasi mikoriza pada tegakan Gmelina arborea. Skripsi. Program Studi Kehutanan Fakultas Kehutanan Universitas Hasanuddin. Makassar.

Karnedi D. 2017. Pengaruh waktu pemberian cendawan mikoriza arbuskular (CMA) terhadap pertumbuhan koro hijau (Macrotyloma uniflrom) sebagai tumbuhan pionir pengembali kesuburan tanah bekas tambang kapur. Skripsi. Program Studi Biologi Jurusan Pendidikan MIPA FKIP Universitas Sanata Dharma. Yogyakarta.

Kormanik PP, Mc. Graw AC. 1982. Quantification of vesicular-arbuscular mycorrhizae in plant roots. in N. C. Schenk $(E d)$. methods and principles of mycorrhizal research. St. Paul The American Pthytopathology Society. Amerika.

Krisdayani PM, Proborini MW, Kriswiyanti E. 2020. Pengaruh kombinasi pupuk hayati endomikoriza, Trichoderma spp. dan pupuk kompos terhadap pertumbuhan bibit sengon (Paraserianthes falcataria (L.) Nielsen). Jurnal Sylva Lestari 1-11.

Kuswandi PC, Sugiarto L. 2015. Aplikasi mikoriza pada media tanam dua varietas tomat untuk peningkatan produktivitas tanaman sayur pada kondisi cekaman kekeringan. Jurnal Sains Dasar 4(1): 17-22.

Mutiarahma EV, Sholichah C, Wirawati T. 2020. pengaruh mikoriza terhadap pertumbuhan tinggi dan diameter semai sengon dari beberapa sumber benih. Jurnal Agrivet 26: 23-30.

Oktaviana G, Yusran, Harso W. 2019. Pemberian dosis inokulum jamur mikoriza arbuskula (JMA) dan pupuk P yang berbeda terhadap serapan $\mathrm{P}$ dan pertumbuhan tanaman jagung (Zea mays L.). Biocelebes 13(2): 142-151.

Pebriansyah A. 2012. Pengaruh cekaman kekeringan dan penambahan fungi mikoriza arbuskula (FMA) terhadap pertumbuhan dan produktivitas beberapa rumput tropika (Chloris gayana, Paspalum dilatatum, dan Paspalum notatum). Skripsi. Departemen Ilmu Nutrisi dan Teknologi Pakan Fakultas Peternakan IPB. Bogor. 
Proborini MW. 2011. Eksplorasi jenis-jenis endomikoriza indigenus pada lahan kering di bali dan pemanfaatannya pada pembibitan mente (Annacardium occidentale L.). Laporan Hibah Doktor. Universitas Udayana. Bali.

Sianturi AF, Subadiyasa NN, Arthagama DM. 2017. Produksi dan mutu tomat (Lycopersicum esculentum Mill.) akibat pemupukan kimia, organik, mineral, dan kombinasinya pada inceptisol kebun percobaan Fakultas Pertanian Universitas Udayana. E-Jurnal Agroekoteknologi Tropika 6(3): 290-300.

Simarmata T, Hindersah R, Setiawan M, Fitriani B, Suriatmana P, Sumarni Y, Arief DH. 2004. Strategi pemanfaatan pupuk hayati CMA dalam revitalisasi ekosistem lahan marjinal dan tercemar. Workshop Produksi Inokulan CMA.

Soverda N. 2010. Pengaruh aplikasi mikoriza vesikular arbuskular (MVA) terhadap pertumbuhan dan hasil tanaman kedelai pada cekaman air. Prosiding Seminar. Fakultas Pertanian Universitas Jambi. Jambi.

Subhan N, Sutrisno, Sutarya R. 2012. Pengaruh cendawan Trichoderma sp. terhadap tanaman tomat pada tanah andisol. Berita Biologi 11(3): 389-400.

Surbakti ESB, Berawi KH. 2016. Tomat (Lycoprsium esculentum Mill.) sebagai anti penuaan kulit. Jurnal Majority 5(3): 73-78.

Syamsiah M, Rahmawati. 2017. Pengujian perlakuan Trichoderma spp. pada media tanam terhadap vigor benih padi pandanwangi cianjur. Jurnal Agroscience 7(2): 266-280.

Triarta NA, Proborini MW, Hardini J. 2019. Peranan FMA Glomus sp. dan pupuk anorganik terhadap produktivitas tanaman kedelai (Glycine $\max (\mathrm{L}$.$) Merrill) var. lokal$ Bali. Jurnal Mikologi Indonesia 3(2): 84-94.

Ulfa M, Waluyo EA, Martin E. 2009. Pengaruh inokulasi fungi mikoriza arbuskula Glomus chlorum, Glomus etunicatum, dan Gigaspora sp. terhadap pertumbuhan semai mahoni dan seru. Jurnal Penelitian Hutan Tanaman 6(5): 273-280.

Valentine K, Herlina N, Aini N. 2017. Pengaruh pemberian mikoriza dan Trichoderma sp. terhadap pertumbuhan dan hasil produksi benih melon hibrida (Cucumis melo L.). Jurnal Produksi Tanaman 5(7): 1085-1092.

Wahyu ER, Purwani KI, Nurhatika S. 2013. Pengaruh Glomus fasciculatum pada pertumbuhan vegetatif kedelai yang terinfeksi Sclerotium rolfsii. Jurnal Sains dan Seni Pomits 2(2): 64-68.

Wicaksono MI, Rahayu M, Samanhudi. 2014. Pengaruh pemberian mikoriza dan pupuk organik terhadap pertumbuhan bawang putih. Jurnal Ilmu-ilmu Pertanian 29(1): 35-44.

Windasari L, Proborini MW, Defiani MR. 2019. Biokontrol endomikoriza terhadap jamur Curvularia sp. penyebab penyakit tanaman jagung (Zea mays L.). Jurnal Simbiosis. 7(2): 28-36.

Yoseva S, Hapsoh, Hartanti I. 2014. Pengaruh pemberian pupuk hayati mikoriza dan rock phosphate terhadap pertumbuhan dan produksi tanaman jagung manis (Zea mays saccharata Sturt). Prosiding Seminar Nasional BKS PTN Barat Universitas Riau. 193-200.

Yusrinawati, Sudantha IM. 2016. Peranan fungi mikoriza arbuskular (FMA) dalam meningkatkan ketahanan kekeringan, ketahanan penyakit, pertumbuhan dan hasil pada tanaman bawang. Thesis. Pascasarjana UNRAM. Mataram. 